\title{
Enunciación
}

\section{El archivo audiovisual y la construcción de la memoria a través del formato documental para televisión ${ }^{1}$}

\author{
The audiovisual archive and the construction of memory through \\ the documentary format for television
}

\author{
Alejandro Alzate Giraldo*(E), Claudia María Maya Franco**(D), Verónica Heredia Ruiz ${ }^{* * *}$ (D)
}

\begin{abstract}
Resumen
Este artículo presenta un análisis sobre el uso del archivo audiovisual como insumo de producciones documentales para la televisión pública, y su papel en la construcción de memoria, tomando como objeto de estudio el archivo audiovisual del canal Telemedellín, construido durante 18 años. En primer lugar, se plantea una revisión de las acepciones más frecuentes del concepto de archivo audiovisual, es decir, las relativas al almacenamiento, el acceso, el uso y su aplicación en los procesos narrativos. En segundo lugar, a través de la aplicación de un instrumento diseñado para esta investigación, se clasifican los documentales encontrados en archivo del canal Telemedellín, rastreando los que en su contenido usan el archivo audiovisual como fuente para su producción. Finalmente, se exponen las conclusiones, entre las que resulta relevante que es frecuente recurrir al archivo audiovisual en estos documentales creados para la televisión pública y que al hacer un uso sustancial del material de archivo crean nuevas narrativas, reactivando materiales ya grabados y aportando a la construcción de memoria.
\end{abstract}

Palabras clave: archivo, audiovisual, televisión pública, memoria, documental.

\begin{abstract}
This article presents an analysis of the use of the audiovisual archive as an input for documentary productions for public television and its role in the construction of memory. Taking as an object of study the audiovisual archive of the Telemedellín channel, an archive built over 18 years. In the first place, a review of the most frequent meanings of the concept of audiovisual archive is proposed, that is, those related to storage, access, use and its application in narrative processes. Second, through the application of an instrument designed for this research, the documentaries found in the archive of the Telemedellín channel are classified, tracking those that use the audiovisual archive as a source for their production in their content. Finally, the conclusions are presented, among which it is relevant that the use of the audiovisual archive is recurrent in these documentaries created for public television and that by making substantial use of archive material they create new narratives, reactivating already recorded materials and contributing to the construction of memory.
\end{abstract}

Keywords: audiovisual, archive, public television, memory, documentary.

1 Artículo del proyecto de investigación "Construcciones discursivas de la memoria, las identidades y las ciudadanías en la televisión a través del formato documental. Caso: archivo documental canal Telemedellín, periodo 1997- 2014", financiado por la Universidad de Medellín y el canal Telemedellín.

* Docente - investigador, Facultad de Comunicación, Universidad de Medellín. Coordinador Centro de Investigación de la misma universidad. Doctor en Estudios Avanzados de Arte Contemporáneo, Facultad de Bellas Artes, Universidad de Barcelona. Máster en Antropología Visual. Máster en Investigación y Producción Artística, Universidad de Barcelona. Correo electrónico: alejandroalzateg@gmail.com

** Profesora Facultad de Comunicación, Universidad de Medellín. Doctora en Filosofía Universidad Pontificia Bolivariana, magíster en Filosofía Universidad de Antioquia, especialista en Psicoanálisis y Filosofía, EAFIT, licenciada en Filosofía Universidad Pontificia Bolivariana. Correo electronico: cmaya@udem.edu.co

*** Docente - investigadora. Decana de la Facultad de Comunicación, Universidad de Medellín. Magíster en Comunicaciones y comunicadora social - periodista Universidad de Antioquia. Correo electrónico: vhruiz@udem.edu.co

Cómo citar: Alzate, A., Maya C. M. y Heredia, V. (2021). El archivo audiovisual y la construcción de la memoria a través del formato documental para televisión. Enunciación, 26(1), 74-90. http://doi.org/10.14483/22486798.16992

Artículo recibido: 16 de septiembre de 2020; aprobado: 23 de julio de 2021 


\section{Introducción}

Este artículo es resultado de un proyecto de investigación, cuyo objeto de estudio fue el archivo audiovisual, en su categoría documental, del canal Telemedellín. Mediante este proyecto se identifica el papel del material de archivo en las narraciones de documentales realizados para televisión pública. La iniciativa tuvo como una de sus hipótesis que la colección de imágenes en movimiento constituye una fuente de información que aporta a la construcción de la memoria, la cual es usada constantemente en los productos documentales realizados por el canal.

Partiendo de esta premisa, se analizó el material audiovisual producido y emitido por el primer canal local creado en Medellín (Colombia) que data de 1997. El propósito de dicho análisis fue a) identificar un corpus de documentales que incluyera el material audiovisual como parte de su producción; b) estudiar el papel que el archivo audiovisual cumple en los formatos documentales producidos y emitidos en el ámbito de la televisión pública, y c) indagar por el papel que dicho archivo audiovisual cumple en la construcción de la memoria de la ciudad de Medellín.

Este análisis implicó el diseño de un instrumento metodológico para el abordaje y estudio de las relaciones entre archivo audiovisual y memoria. A partir de la aplicación del instrumento se puso de manifiesto la importancia del archivo audiovisual en la construcción de memoria, lo cual le confiere un papel preponderante en el modo en que, cuando la sociedad es narrada, esta se concibe como parte de un grupo social que pertenece a la ciudad. Dicha función vincula estrechamente el documental para televisión con la construcción de la memoria colectiva en una contingencia histórica, en la que la atención está volcada sobre el modo en que podemos relacionarnos con el pasado, tanto de forma individual como colectiva.

\section{Puntos de partida: definiciones y conceptos de archivo y colecciones audiovisuales}

Las imágenes del pasado han sido utilizadas de diversas formas. Este artículo no se concentra en el análisis de los usos narrativos del archivo en películas de montaje. Sin embargo, hablar de archivo audiovisual siempre va a estar asociado al concepto de found footage, el cual Noriega (2012) describe como "una visión performativa del archivo ligada al uso, al re-uso y a la apropiación de lo que se considera archivo cultural y que muchas veces coincide con el material audiovisual encontrado" (p. 137). Así mismo, este tipo de creaciones con material de archivo abordan conceptos como el de home movies. En relación con este recurso, Veliz (2020) explica: "las imágenes de un filme familiar funcionan menos como representaciones que como índices que invitan a volver sobre el pasado vivido" (p. 5). Esta relación con el pasado no siempre asegura una veracidad, ya que se puede tener en cuenta los falsos documentales, Gómez Martínez y Casal Balbuena (2015) explican:

[...] se le considera heredero de los fakes televisivos (también denominados fakery, en plural, fakeries) en los que se ponía a prueba, ya en los años cincuenta, las tragaderas del público más confiado mediante la difusión de "falsas noticias" de naturaleza generalmente anecdótica (p. 327-328).

Los Ilamados fakes, o falsos documentales, están propiamente estructurados a partir del material de archivo. Este es solo uno de los ejemplos de las diversas formas como pueden ser interpretados y usados en función del objetivo de los realizadores audiovisuales. El presente artículo se concentra en las colecciones audiovisuales y el uso del material de archivo en los documentales para televisión y las posibilidades que los canales tienen para volver a usar su propio material para nuevas narraciones. Al respecto, Lanza (2010) plantea usos como ilustración, evocación e instrumento de denuncia. 
El corpus de esta investigación es la colección del canal Telemedellín, con el fin analizar las posibilidades de las colecciones audiovisuales de los canales públicos, las cuales pueden ser usadas como fuente de nuevas narrativas, memoria y reelaboración de contenidos.

El concepto de archivo remite a la idea de origen. Según Frutos (2008), "el término 'archivo' proviene del latín archivum, significa 'edificio público' y del griego archeion, que quiere decir 'lugar que ocupa el magistrado superior'. Proceden del arche, que tiene significados múltiples como 'origen', 'poder' y 'principio'" (p. 3). Para hablar de archivo audiovisual, entendemos su fusión con la imagen y el sonido. Esta fusión de imágenes en movimientos y archivo es explicada por Edmonson (2004) de la siguiente manera:

Cada vez se emplea más como término único de gran utilidad, abarca por igual las imágenes en movimiento y los sonidos grabados de todo tipo. La Unesco agrupa a los archivos cinematográficos, de televisión y de sonidos, los cuales, aunque tienen origen diverso, han ido encontrando puntos en común mediante el cambio tecnológico. (p. 19)

Así, se entiende archivo como el ordenamiento y recolección de una serie de piezas agrupadas de forma sistemática con los requerimientos necesarios para su conservación, visualización y disponibilidad para su uso, en la norma de tratamiento para el archivo, que forma parte del programa Memoria del Mundo, de la Unesco. Para Edmonson (2004), "un archivo audiovisual es una organización cuyo cometido podrá estar establecido por ley, consiste en facilitar el acceso a una colección de documentos audiovisuales y del patrimonio audiovisual mediante actividades de acopio, gestión, conservación y promoción" (p. 27).

La recopilación, acumulación, preservación y transmisión de información que contienen los archivos audiovisuales aporta el resurgimiento de nuevos conocimientos a partir de experiencias, textos, obras y documentos que son conservados en el tiempo. Históricamente, el material de archivo ha sido destruido y manipulado en función de intereses particulares. A esta desaparición y acceso restringido contribuyen también las políticas de conservación en lo referente a formatos, soportes, sistemas de reproducción y otras condiciones técnicas que obedecen no solo al carácter de imagen sino al desarrollo en sí mismo de políticas mundiales de conservación, acceso y difusión de estos materiales.

Respecto de la salvaguarda y la conservación de imágenes en movimiento, es fundamental tener en cuenta las recomendaciones que plantea la Unesco desde 1980, en las que se entiende el material de archivo como una expresión de la personalidad cultural de los pueblos y una forma fundamental de registrar la sucesión de acontecimientos y las dimensiones que estos aportan. Es fundamental su conservación para la construcción de memoria. Assmann, (citado por Seydel, 2014), describe "los procesos de estabilización de la memoria cultural en que intervienen las diversas instituciones y medios [y] explora los procesos de dinamización de la memoria cultural que se producen en nuestras sociedades actuales mediáticas a través de la remediatización" (p. 178).

En una entrevista realizada por Rubín de Celis (2010) al documentalista Patricio Guzmán, se resalta la importancia del archivo en ella menciona: "Trabajar con la memoria es muy importante, no se trata de trabajar con el pasado no para recordarlo, sino para incorporarlo al presente, porque, de alguna forma el pasado, es una representación de nuestra identidad" (p. 274). Esta incorporación al presente tiene que ver directamente con el papel que este archivo puede tener en los medios de comunicación. Teniendo en cuenta lo anterior, Hagedoorn (2013, citado por Bossay et al., 2021) se refiere a estas imágenes como:

El repertorio híbrido de la memoria utiliza la historia de la propia televisión, y la creación de propios archivos de los canales, como un elemento esencial de las múltiples plataformas a través de las cuales se puede ver hoy televisión [...]. Así, una visión 
televisada del pasado, tanto en ficción como en el documental, y en otros géneros televisivos -educacional y de reportaje, por ejemplo- ha aportado irrevocablemente a la creación y repetición de un imaginario de la historia de las naciones. (p. 18)

El uso del archivo es mucho más que una herramienta narrativa con características formales establecidas. A continuación, profundizaremos en la imagen de archivo como material probatorio de la realidad abordada por Lanza (2010), la construcción de memoria y el proceso de ilustración

\section{El archivo como prueba, ilustración o memoria}

Un ejemplo para entender el uso del archivo como prueba y construcción de memoria es el Archivo Nacional de la Memoria de la Ciudad de Buenos Aires, el cual es el responsable de la preservación y el estudio de la documentación asociada a las violaciones de los derechos humanos en Argentina. Incluye la custodia y análisis de los testimonios que integran el archivo de la Comisión Nacional sobre Desaparición de Personas. Además, se encarga de la obtención, análisis, clasificación, duplicación, digitalización y almacenamiento de testimonios y documentos sobre el quebrantamiento de los derechos humanos y las libertades fundamentales en que esté comprometido el Estado argentino, y sobre la respuesta social e institucional ante violaciones de derechos humanos. El Archivo Nacional de la Memoria de la Ciudad de Buenos Aires ha sido pionero en América Latina en el uso de documentos como prueba y elemento para la judicialización, dando al formato documental un carácter jurídico en la comprobación de los crímenes. Este tipo de archivos operan activamente en los procesos de reparación en contextos de violencia, como el que ha vivido la ciudad de Medellín. Así, los archivos no solo son fuente de narrativa, sino que también son herramientas para la ciudadanía en lo relacionado a los derechos humanos y a la configuración de las relaciones menos traumáticas con el pasado.
En cuanto a las relaciones con el pasado y hechos traumáticos, los procesos de memoria y reparación han sido llevados a cabo por diversos colectivos y asociaciones de víctimas, así como por los gobiernos de diversos países, dándole un papel social al archivo. Seydel (2014) afirma que las marcas institucionales, territoriales: "Se trata de expresiones producidas por actores y movimientos sociales diversos y por políticas estatales que responden a las demandas de estos actores sociales; algunas veces ocupando posiciones en el Estado" (p. 226). Colombia, por su larga historia de violencia, no es la excepción. En el caso del corpus documental analizado, se evidencia el alto número de documentales cuyo tema es la violencia (inseguridad, narcotráfico, bandas delincuenciales), con lo que revisitar el pasado a partir de dicho material permite relacionarse con posibles explicaciones sobre una historia de violencia que no ha parado en el país.

En Medellín, los archivos de prensa día tras día son visitados por víctimas para documentar su condición, el archivo se convierte en una prueba para demostrar la condición de victima. Así como la prensa constituye un elemento probatorio del pasado, de los hechos y situaciones vividas, la imagen de archivo constituye una prueba que permite, tanto a los espectadores como a los investigadores, generar un puente directo de tiempo entre el pasado y el presente que posibilita no solo la corroboración o prueba de lo sucedido, sino dar una visión actual de los hechos o acontecimientos del pasado. Cada vez es más frecuente la presencia de los productos audiovisuales en la sociedad de la información y, sin embargo, la vida útil de estos productos es muy corta, se usan solo para una emisión. En este sentido se resalta la importancia de almacenar y revisar de nuevo estas producciones audiovisuales, ya que son fundamentales para la construcción de memoria. Esta situación ya fue expuesta por la Unesco en 1980, que aprobó en su Conferencia General una serie de recomendaciones para la salvaguardia y conservación de 
las imágenes en movimiento. Ronco-López (2009) afirma lo siguiente:

El pasado como entidad fundamental para la construcción de un presente sustenta las normas e intereses de Naciones Unidas para la conservación de los documentos audiovisuales, más allá de ese carácter anecdótico con el que se ha caracterizado el archivo, las funciones fundamentales del archivo se han establecido a través de una serie de usos que han hecho fundamental la conservación de la memoria. (p. 1)

El Consejo de Coordinación de las Asociaciones de Archivos Audiovisuales (CCAAA) ejecuta proyectos en apoyo a los acervos audiovisuales en todo el mundo, a través de esfuerzos para conservar estos documentos con las dificultades que ello implica. El esfuerzo de conservación ha implicado un sinnúmero de impactos. Uno de ellos es la sobreprotección del archivo, lo cual ha generado dificultades de acceso. En Colombia la academia y entidades como la Fundación de Patrimonio Fílmico, y el Ministerio de Cultura y su Dirección de Cinematografía han creado estrategias que posibilitan avanzar cada vez más en este campo.

En cuanto a la parte normativa en el contexto colombiano, la Ley 397 de 1997 (Ley de Cultura) establece que el Gobierno nacional "velará por la recuperación, conservación y preservación del patrimonio colombiano de imágenes en movimiento" (parágrafo único del artículo 12 del patrimonio bibliográfico, hemerográfico, documental y de imágenes en movimiento). En torno a la conservación, el Decreto 358 de 2000 reglamenta algunos aspectos relacionados con la Ley de Cultura y define tanto los elementos físicos que constituyen las matrices de la obra audiovisual como la obra en sí misma que pertenezca a la cinematografía nacional debe ser declarada bien de interés cultural. La naturaleza del archivo audiovisual es diversa, proviene de la cinematografía, la radio y la televisión, y está explícito en las normas la importancia de la conservación de este.

\section{Documental en la televisión pública}

El documental nace con el cine. Las primeras películas de los hermanos Lumière registraron eventos de la vida cotidiana como La llegada del tren o La salida de la fábrica, que dieron cuenta del potencial expresivo y narrativo de la imagen en movimiento. En este orden de ideas, y como lo señala Nichols (1991), el documental cumple con la función y responsabilidad de "describir e interpretar el mundo de la experiencia colectiva" (p. 40). Primero en el cine, luego en la televisión, el documental cumple la función de ser un documento audiovisual que da cuenta de unas realidades, interpretando sentidos y significados a la vida de la gente. Así mismo, el documental se encarga de generar una reinterpretación de la realidad. Como resalta Barroso (2009), "la realidad es interpretada y analizada desde la subjetividad del cineasta y de las pautas culturales de su contexto histórico, industrial o social" (p. 93). Asociado a la televisión, el documental se encarga de construir retratos de los espectadores y es así como Comolli (2007) lo nombra de la siguiente manera: "la gente tiene la necesidad de la tele porque toda sociedad necesita imágenes de sí misma, de sus prójimos, de sus distantes" (p. 106).

Precisamente, el formato documental ha estado presente en la televisión como una pantalla donde los ciudadanos se reconocen e identifican unos a otros, y ha tenido una mayor presencia en aquella de carácter público, pues por las características de su formato responde a las necesidades, intereses y expectativas de la audiencia.

La televisión pública ha sido entendida como aquella que privilegia el carácter de servicio públi$\mathrm{co}$, en la medida que promueve el reconocimiento de las audiencias en su rol de ciudadanos más que de consumidores (Rincón 2005). Por su parte, Banerjee (2005) afirma que el rol principal que cumple la televisión pública es proporcionar a los ciudadanos el acceso y la participación en la vida pública, además de facilitar el acceso a la educación y a la cultura. Es así como este tipo de televisión Unesco (2006) "se dirige a todos los públicos, 
especialmente a las minorías, busca el reconocimiento, la inclusión social a través de contenido variado y de calidad que refleje las necesidades, preocupaciones, expectativas de diversas audiencias" (p. 8). Mazziotti (2001) afirma lo siguiente:

De hecho, la importancia de la televisión pública en las sociedades modernas radica en que esta promueve la participación ciudadana, el sostenimiento de la diversidad cultural y la defensa de la libertad de expresión como base para la democracia. En consecuencia, busca [...] hacerse cargo de lo que deja vacante la televisión comercial y necesita tener en cuenta la diversidad cultural, la tolerancia y la apertura hacia otros sujetos culturales. (pp. 184-185)

Lo anterior pone de manifiesto la importancia que posee el archivo en el contexto de la televisión pública, a pesar de que, en muchos casos, dicha importancia es de carácter pragmático, como lo reconoce Caldera Serrano (2014):

El archivo cumple en muchos casos una función que no va más allá de servir como recurso facilitador de la agenda setting o incluso para poblar la programación con la nostalgia de lo viejo: los archivos de televisión existen porque abaratan los procesos de producción de nuevos productos audiovisuales [...]. Por lo tanto, los archivos audiovisuales televisivos existen porque tienen rentabilidad empresarial, económica y funcional. (p. 81).

Esta función pragmática, quizá la principal del archivo en la televisión local da espacio en el ámbito de lo público para una ampliación del uso del archivo que permite vincularlo a procesos sociales de radical importancia en sociedades en las que se plantea como un imperativo la reconstrucción del tejido social y de la relación con el pasado.

\section{Metodología y formas de análisis}

Para la investigación se realizó una revisión de 113 documentales producidos durante 18 años por el canal Telemedellín. Para ello fue construida una herramienta cualitativa, apoyada en la recolección de datos cuantitativos que permitió la identificación, clasificación y análisis de los formatos documentales que usan materiales de archivo en su estructura narrativa.

El instrumento diseñado para la investigación, además de ser útil para el análisis del corpus seleccionado, podría ser replicado en otros canales públicos para el estudio del archivo. Dicho instrumento permite la identificación del producto, incluyendo su ficha técnica, el material de archivo, los temas y el desarrollo de conceptos, como el de memoria, en los documentales. Además, Gómez-Tarín (2006), en sus estudios desde el análisis fílmico, plantea "la importancia de descomponer los materiales a analizar, desde sus elementos constituyentes [y] establecer relaciones entre tales elementos para comprender y explicar los mecanismos que les permiten constituir un todo significante" (p. 3).

Fue necesaria para la clasificación del corpus documental, la visualización del material, lo cual implicó afinar la mirada con relación a los matices que vinculan dicho corpus con el concepto de memoria. El instrumento finalmente desarrollado ofrece por tanto múltiples entradas y posibilidades para el análisis entre las que, a efectos del presente artículo, pondremos de relieve las que tienen que ver con archivo y construcción de memoria. Lo anterior permite, a su vez, avanzar hacia el propósito de dar cuenta del papel determinante del archivo audiovisual. La tabla 1 detalla el instrumento diseñado.

\section{Análisis y resultados}

En total se analizaron 113 documentales, de los cuales $46 \%$ usan material de archivo para el desarrollo del contenido, lo que apunta a que $54 \%$ restante no usan material de archivo. En la tabla 2 se describe cómo fueron clasificados los documentales que incorporan el archivo en su contenido.

En los contenidos documentales clasificados fue analizado el concepto de memoria, 
Tabla 1. Instrumento de análisis aplicado a la colección audiovisual Canal Telemedellín

\begin{tabular}{|c|c|c|c|c|}
\hline \multicolumn{5}{|c|}{ Ficha de análisis documentales Telemedellín } \\
\hline \multicolumn{5}{|c|}{ Identificación del contenido } \\
\hline Número ficha & $\begin{array}{l}\text { Código } \\
\text { documental }\end{array}$ & Título & Fecha de realización & Fecha de emisión \\
\hline $\begin{array}{l}\text { Tipo (serie o } \\
\text { unitario) }\end{array}$ & Duración & Tipo de contenido & $\begin{array}{l}\text { Ámbito (local, regional, } \\
\text { nacional, internacional) }\end{array}$ & Participantes \\
\hline Director (es) & & Sonidista (s) & Fotografía & Montaje \\
\hline \multicolumn{5}{|l|}{ Sinopsis: } \\
\hline \multicolumn{5}{|c|}{ Temas abordados en los documentales: } \\
\hline Temas principales & & Temas sexcundarios & & \\
\hline \multicolumn{5}{|c|}{ Desarrollo de conceptos } \\
\hline Memoria & & Ciudadanías & & \\
\hline \multicolumn{5}{|c|}{ Identificación del material de archivo en los contenidos documentales } \\
\hline \multicolumn{5}{|c|}{$\begin{array}{l}\text { ¿Contiene material de archivo? Material de archivo } \quad \text { ¿No contiene material de archivo? } \\
\text { Expositivo }\end{array}$} \\
\hline Observaciones: & & & & \\
\hline
\end{tabular}

Fuente: elaboración propia.

Tabla 2. Clasificación de los documentales que usan material de archivo en toda la colección audiovisual del canal

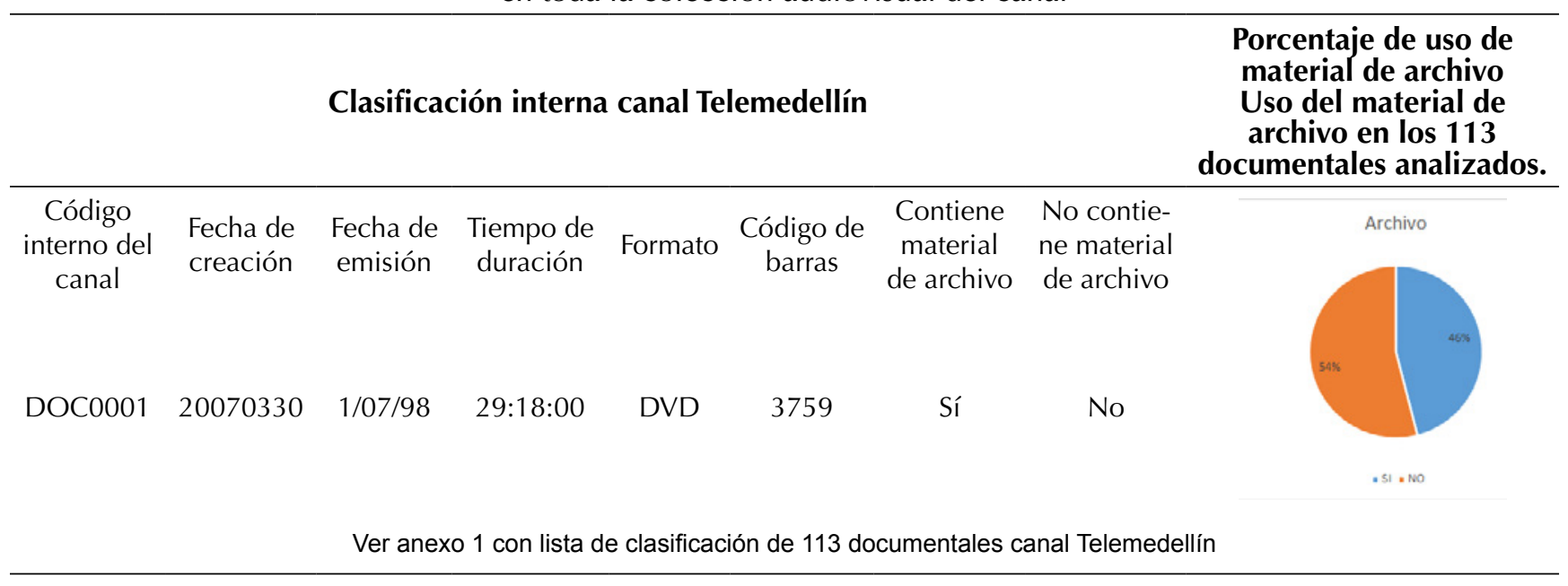

Fuente: elaboración propia.

enarbolado, entre otros, por Durkheim (citado por Bergalli y Rivera, 2010), para quien se configura como "un conjunto de creencias y sentimientos comunes al término medio de los miembros de una misma sociedad, que constituyen un sistema determinado que tiene vida propia" (p. 6), toda vez que configuran modalidades de apropiación del pasado con finalidades específicas. La memoria colectiva es la que se construye entre todos los ciudadanos, a diferencia de la historia, que la escriben unos cuantos y en la que, con frecuencia, la colectividad no se ve representada. La historia 
requiere que los hechos estén, por decirlo así, consumados, la memoria colectiva, a diferencia de esta, participa, en cuanto agente activo de la interpretación, no solo en la recopilación de los datos del pasado sino en su reconstrucción.

En este sentido resultan pertinentes los aportes de Halbawchs (2002). La memoria es un producto de interacción cultural colectiva que fundamenta el discurso de los individuos, fusiona los hechos del pasado y del presente. El documental es, junto con los libros, los museos, las películas, la fotografía, el arte, uno de los productos de esta materialización de la memoria. En este, la memoria se sedimenta en la narración de contenidos sociales, así como en el potencial de comunicabilidad que el documental les confiere a estos.

Por lo anterior, podemos afirmar que el documental constituye un prolífico objeto de investigación para las ciencias sociales y que puede dar luces importantes en relación con el análisis político, histórico y social. Por otra parte, releva la investigación archivística eminentemente discursiva, poniendo a la imagen en movimiento como fuente de reflexión y análisis. El encuentro con los documentales que constituyeron el corpus del proyecto de investigación referido en este artículo nos puso frente a la historia como acontecimiento siempre vivo, como memoria activa. Lo anterior asumiendo el documental como uno de los soportes de los medios de comunicación masiva que se relacionan de modo directo con los procesos sociales históricos y políticos de América Latina, Colombia y Medellín.

El corpus documental identificado reveló ciertas características: narra las historias de la ciudad de Medellín, y recorre los barrios y las comunas de la ciudad a través de la mirada de los realizadores, así como de los habitantes que devienen personajes en los que pueden reconocerse, así como en quienes se reconstruyen, características sociales y culturales que trascienden la ciudad de Medellín, narrando también historias del departamento de Antioquia e incluso del país. Cuenta también las historias de los habitantes de la ciudad retratando sus problemáticas, sus modos de pensar y de concebirse a sí mismos como medellinenses. Se trata de un material diverso y de un gran aporte para la reconstrucción y comprensión de nuestro pasado, de un valioso archivo que cumple su mayoría de edad.

Los aspectos del instrumento, que más directamente le apuntan a la construcción de la memoria histórica a través del documental, nos llevaron a crear una subcategoría en el corpus de documentales cuyo criterio fue el de documentales cuyo insumo haya sido el material de archivo. Este criterio delimitó un grupo de 52 documentales. La tabla 3 ejemplifica, con 5 documentales que se identificaron que cumplen con la categoría de memoria, estos 5 documentales son parte de los 52 que contienen material de archivo. Adicionalmente, presenta una breve sinopsis del documental y describe el tipo de material de archivo utilizado.

El resultado de esta clasificación nos permitió delimitar este subgrupo de documentales según otras categorías, como la temática y la función que se le dio al material de archivo en el documental. Fueron subsidiarios de esta clasificación elementos tomados de la teoría de la enunciación, porque nos permitieron identificar quiénes hablan en los documentales, es decir, personajes; la intención con la que hablan, aquellos a quienes se dirigen, entre otros. Estos elementos, sumados al análisis de la presencia de memoria arrojada por la visualización, nos ayudaron a esclarecer la función que, en estos documentales, se le da al material de archivo y, lo más importante, su vínculo con la memoria. La tabla 4 muestra los elementos de esta segunda parte del análisis y dos ejemplos de su implementación.

La memoria desde el punto de vista de la noción de archivo documental adquiere una doble naturaleza: por un lado, como objeto de investigación y, por otro, como insumo en la producción de nuevo material audiovisual. En efecto, los productos de la investigación fueron dos documentales en los que el archivo audiovisual se utilizó como insumo. 
Tabla 3. Ejemplo de análisis de documentales que usan el material de archivo en sus narraciones

\begin{tabular}{|c|c|c|}
\hline Documental y director & Sinopsis & Presencia y tipo del material de archivo \\
\hline $\begin{array}{l}\text { Conciliación y reparación } \\
\text { Ángela Pineda }\end{array}$ & $\begin{array}{l}\text { La organización Fuerza Joven ha logrado hacer } \\
\text { que personas de los barrios más golpeados por } \\
\text { la violencia en Medellín dejen de delinquir y } \\
\text { se unan a ellos. }\end{array}$ & $\begin{array}{l}\text { Testimonios de transformación de personas } \\
\text { directamente golpeadas por la violencia. }\end{array}$ \\
\hline $\begin{array}{l}\text { Entrampados } \\
\text { Luis Alirio Calle }\end{array}$ & $\begin{array}{l}\text { Este documental narra cómo los jóvenes de } \\
\text { los barrios están entrampados en la ilegalidad, } \\
\text { cómo buscan la manera de salir de esta a través } \\
\text { de la paz entre los combos barriales. }\end{array}$ & $\begin{array}{l}\text { Entrevistas a los líderes, desmovilizados y a los } \\
\text { funcionarios públicos. } \\
\text { Narración que hace Luis Alirio Calle. } \\
\text { Imágenes de archivo y dramatizados. } \\
\text { Hiphop que narra la experiencia. }\end{array}$ \\
\hline $\begin{array}{l}\text { Plaza Gardel en Medellín } \\
\text { Federico Benítez }\end{array}$ & $\begin{array}{l}\text { La historia de la muerte de Gardel y su legado } \\
\text { en la ciudad de Medellín son el contexto para } \\
\text { la Inauguración de la Plaza Gardel cerca del } \\
\text { Aeropuerto Olaya Herrera en } 2003 \text {. }\end{array}$ & $\begin{array}{l}\text { Discurso de Luís Pérez Gutiérrez. } \\
\text { Imágenes de archivo. }\end{array}$ \\
\hline $\begin{array}{l}\text { La cruz } \\
\text { Alonso Ernesto Manrique }\end{array}$ & $\begin{array}{l}\text { Historia de los desplazados y su muy difícil } \\
\text { experiencia de vida en la ciudad de Medellín. }\end{array}$ & $\begin{array}{l}\text { Testimonios, música, imágenes de las actuales } \\
\text { viviendas de los desplazados, textos. }\end{array}$ \\
\hline $\begin{array}{l}\text { Fútbol sin violencia } \\
\text { Fernando Cortés Vera }\end{array}$ & $\begin{array}{l}\text { Medellín vive la pasión del fútbol semana tras } \\
\text { semana. Miles de personas siguen a sus equi- } \\
\text { pos a lo largo del año, celebrando sus triunfos } \\
\text { y sufriendo con sus derrotas. }\end{array}$ & Entrevistas, ilustraciones, fotografía. \\
\hline
\end{tabular}

Fuente: elaboración propia.

Tabla 4. Funciones del material de archivo

\begin{tabular}{|c|c|c|c|}
\hline $\begin{array}{l}\text { Nombre del } \\
\text { documental, } \\
\text { director, temática }\end{array}$ & $\begin{array}{c}\text { Material de archivo } \\
\text { utilizado }\end{array}$ & $\begin{array}{l}\text { Función del } \\
\text { material de } \\
\text { archivo }\end{array}$ & Relación con la construcción de la memoria \\
\hline $\begin{array}{l}\text { Conciliación y } \\
\text { reparación } \\
\text { Ángela Pineda } \\
\text { Violencia y conflicto }\end{array}$ & $\begin{array}{l}\text { Testimonios de trans- } \\
\text { formación de personas } \\
\text { directamente golpea- } \\
\text { das por la violencia. }\end{array}$ & $\begin{array}{l}\text { Manifestar una } \\
\text { postura de apoyo } \\
\text { a los procesos de } \\
\text { reconciliación. }\end{array}$ & $\begin{array}{l}\text { El documental pretende incidir directamente en la modifica- } \\
\text { ción de imaginarios y prejuicios respecto de los reinsertados } \\
\text { y muestra que es posible la reconciliación. }\end{array}$ \\
\hline $\begin{array}{l}\text { El hacedor de } \\
\text { imanes } \\
\text { Fabián Rodríguez } \\
\text { Agonía y muerte } \\
\text { del Ferrocarril de } \\
\text { Antioquia }\end{array}$ & $\begin{array}{l}\text { Fotografías, videos, } \\
\text { entrevistas. }\end{array}$ & $\begin{array}{l}\text { Poner de mani- } \\
\text { fiesto el contraste } \\
\text { entre el ayer y } \\
\text { el hoy tomando } \\
\text { como referente el } \\
\text { disuelto Ferroca- } \\
\text { rril de Antioquia. }\end{array}$ & $\begin{array}{l}\text { Se pone el énfasis en recordar las divisiones radicales que } \\
\text { existen entre los sectores pudientes de la población, que han } \\
\text { viajado, que han estudiado y que tienen el poder para em- } \\
\text { prender proyectos como el de las FF. AA., despilfarrando en } \\
\text { ocasiones el presupuesto, cometiendo errores monumenta- } \\
\text { les incluso a partir de motivaciones personales... Y por otro, } \\
\text { el de una ciudadanía humilde e indiferente, que no cuida, } \\
\text { sino que se apropia y que por sí misma no hace más que } \\
\text { adecuarse a lo que suceda. Se construye una representación } \\
\text { de ciudadanos en quienes la pujanza, el emprendimiento y } \\
\text { lo que se suele denominar la verraquera, en casos como el } \\
\text { del Ferrocarril de Antioquia obedecen más a la ostentación } \\
\text { que a proyectos que puedan ser sostenibles. También la de } \\
\text { ciudadanos abusivos, que se apropian de las estaciones, y } \\
\text { solapados, que se esconden cuando ven las cámaras. Tam- } \\
\text { bién, en mecánicos que encuentran en el camino, y sobre } \\
\text { todo en doña Aurora Carmona, personas amables, buenas, y } \\
\text { en el caso de ella, incluso admirables. }\end{array}$ \\
\hline
\end{tabular}

Fuente: elaboración propia 


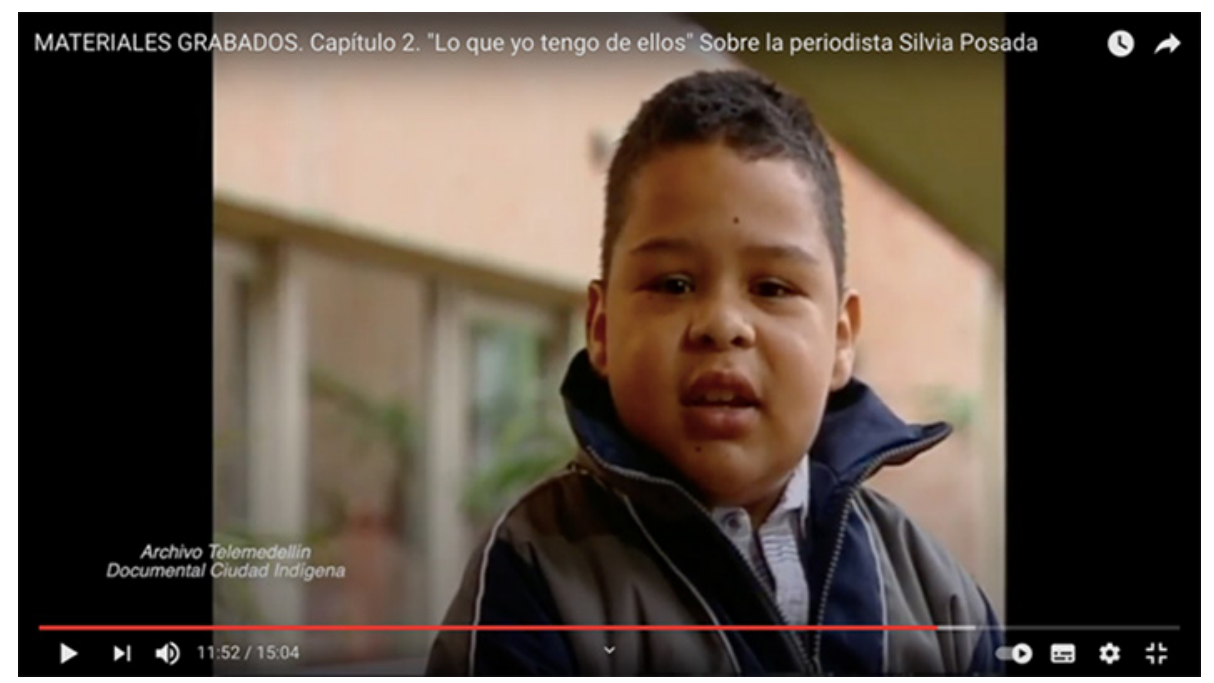

Figura 1. Captura de pantalla de la serie documental Materiales grabados, realizada como parte del proyecto de investigación

Fuente: Alzate (2017).

La reelaboración, ya no solo individual del pasado, sino también colectiva, solo es posible cuando los sujetos pueden verse en contexto, es decir, con los otros, como parte de una sociedad. Seydel (2014) plantea que "pese a que la rememoración individual se organiza dentro de los marcos sociales existentes, es condicionada por la psicología social y construida socialmente y pese a que el individuo participa de la memoria colectiva, el colectivo como tal no tiene" (p. 194).

Este análisis nos permitió encontrar casos paradigmáticos de uso del archivo audiovisual en relación con la construcción de memoria. A continuación, analizaremos el papel que cumple el archivo en los documentales encontrados dentro del corpus analizado a partir de las categorías enunciadas en la metodología, a saber: uso del material de archivo, tipo de material utilizado, temática abordada, función del material y relación con la construcción de memoria.

Un ejemplo de la presencia del archivo audiovisual como prueba o testimonio es el documental Corazones desarmando de Ana María Guarín, que recibió el premio Avina de investigación periodística. Evidencia el uso del material de archivo para corroborar un hecho de la historia colombiana relacionado con los procesos de desmovilización por parte de las Autodefensas Unidas de Colombia entre los años 2008 y 2009. Las colecciones audiovisuales en el documental tienen una función de recuperación de la memoria, por cuanto permiten establecer un vínculo con acontecimientos que han marcado los procesos históricos, en este caso del conflicto armado en Colombia; contextualiza además el Acuerdo de Paz firmado en septiembre de 2016 y el acercamiento a los procesos de posconflicto.

En este documental, el material de archivo permite abordar el difícil tema de la reinserción social y económica dentro de la legalidad y el proceso de reintegración social y esto lo logra presentando el proceso de diferentes desmovilizados de grupos al margen de la ley. Así, construye a través de las historias, personajes y material de archivo, la memoria de las experiencias de reinserción. El documental le da la voz a desmovilizados mostrando que de nuevo forman parte de la población civil, contribuyendo a su reconocimiento como tales. También contribuye a que se reconozca la existencia de un conflicto que ha hecho parte por décadas de nuestra memoria individual y colectiva. 
Desde el punto de vista de la situación de enunciación, podemos reconocer diversas voces narrativas, encarnadas en varios de los personajes, así como sus aspectos racionales y emocionales. Los personajes hablan desde su experiencia. Está el caso de una mujer desmovilizada de la guerrilla cuyo hijo nace en un atentado en el que su esposo muere asesinado:

Lo más duro para mí cuando estaba dentro del grupo era que me faltaban mis hijos [...]. Uno ser madre es lo más duro y más tocarle a uno ser madre en una organización de esas, me iban a hacer abortar, pero la droga llegó cuando yo tenía seis meses, como yo engordo tanto en los embarazos por eso no me la pusieron [...]. La motivación mía fue por el niño, el niño fue capturado por los de Bienestar Familiar [...]. El día que fuimos a verlo estaba cumpliendo 6 meses, yo apenas lo vi me puse a llorar [...] ¿si no me da miedo saber que estaban asesinando desmovilizados? Sí, uno siente miedo.

El hecho de contar la historia desde los testimonios de los desmovilizados le confiere una fuerte carga emocional que aporta, a su vez, a la recordación por parte de quienes no han vivido el conflicto de modo directo. También es notoria, no obstante, la intencionalidad estatal de presentar los procesos de reinserción desde sus aspectos exclusivamente positivos, así como la de enfatizar en las palabras violencia, reparación, trabajo. Contribuyen a acentuar esta dimensión emocional, la música y las imágenes de apoyo desarrolladas mediante secuencias de recorridos del personaje. Se logra así suscitar sensibilidad en el auditorio respecto de lo que significa vivir en medio de la guerra.

\section{Conclusiones}

El estudio realizado posibilita una reflexión mediante el análisis cualitativo que clasifica las diferentes temáticas, la presencia del concepto de memoria y el uso del archivo en los contenidos analizados. Lo anterior abre un espacio para generar preguntas, teniendo en cuenta que es un material que permite una interpretación subjetiva, asociada a la época, al contexto y a los elementos formales referentes al sonido y la imagen de cada contenido. Sin embargo, respecto del número de documentales del corpus general que usan material de archivo como elemento narrativo, bien sea como prueba, referente fáctico o búsqueda de causalidades es muy alto. El hallazgo que resulta llamativo refiere la importancia de la presencia del archivo en las producciones documentales de la televisión pública, está asociado a que en el $46 \%$ de los documentales analizados se utiliza el material de archivo como insumo de la narración, porcentaje equivalente a 52 documentales, lo que expresa que el $54 \%$ de los documentales estudiados no usan material de archivo, una cantidad correspondiente a 61 documentales.

El material analizado nos muestra la importancia del acceso al archivo audiovisual para la construcción de memoria, para tener una prueba de lo sucedido y como un insumo fundamental para la construcción de nuevas narrativas. Estas aportan a la construcción de lo histórico, reforzando aspectos emotivos y posibilitando la activación de funciones, con carácter epidíctico: conmemorar, recordar y rendir tributo.

La importancia de este estudio radica en que en el formato documental la memoria confiere un papel preponderante en el modo en que, al ser narrados, nos concebimos como parte de un grupo social. Esta característica del documental se evidencia en su capacidad de entrar en relación con lugares, situaciones y personajes. Otorgándoles, a su vez, un papel protagónico en la construcción de la narración. Lo anterior supone una dialéctica en la que el documental está determinado por su relación con sus contenidos y, a su vez, aquello que forma parte de la narración, es construido y pasa a ser parte importante de nuestra memoria colectiva, del modo en que nos vemos y de la posibilidad, siempre renovable, de volver a vernos. 


\section{Reconocimientos:}

El presente trabajo es resultado del proyecto "Construcciones discursivas de la memoria, las identidades y las ciudadanías en la televisión a través del formato documental. Caso: archivo documental Canal Telemedellín, periodo 1997- 2014". Financiado por la Universidad de Medellín y el canal Telemedellín.

\section{Referencias bibliográficas}

Alzate Giraldo, A. (10 de febrero de 2017). Materiales grabados. Capítulo 2. "Lo que yo tengo de ellos". Sobre la periodista Silvia Posada [Archivo de video]. YouTube. Recuperado de: https://www.youtube.com/watch? $v=301 \mathrm{jTw} O u n 1 \mathrm{E} \& \mathrm{t}=634 \mathrm{~s}$

Banerjee, I. (2005). Radiotelevisión de servicio: un manual de mejores prácticas. Unesco. Recuperado de: http://unesdoc.unesco.org/images/0014/001415/141584s.pdf

Bergalli, R. y Rivera, I. (2010). La memoria colectiva como deber social. Memoria Colectiva como deber social. Barcelona: Anthropos.

Barroso, J. (2009). Realización de documentales y reportajes. Editorial Síntesis.

Bossay, C., Marzorati, Z. y Pombo, M. (2021). Prefacio. El audiovisual expandido. Cuaderno, 95, 15-24. doi: https://doi.org/10.18682/cdc.vi95

Caldera Serrano, J. (2014). Production research: el nuevo rol profesional para nuevos tiempos en la gestión de la información audiovisual. Investigación Bibliotecológica, 29(66), 79-89. doi: https://doi.org/10.1016/j.ibbai.2016.02.026

Comolli, J. (2007). Ver y poder. La inocencia perdida: cine, televisión, ficción, documental. Aurelia Rivera.

Decreto 358 de 6 de marzo de 2000. Por el cual se reglamenta parcialmente la Ley 397 de 1997 y se dictan normas sobre cinematografía nacional. Diario Oficial, CXXXV(43932), 14.

Edmondson, R. (2004). Filosofía y principios de los archivos audiovisuales. Organización de las $\mathrm{Na}$ ciones Unidas para la Educación, la Ciencia y la Cultura.
Frutos, J. (2008). Un fondo patrimonial de la sombra: la Linterna Mágica. Universidad de Granada.

Gómez Martínez, P. J. y Casal Balbuena, M. (2015). Falso documental y retórica: una exploración desde el contenido y sus efectos Opción, 31(1), 2015, 324-337. https://www.redalyc.org/ pdf/310/31043005018.pdf

Gómez-Tarín, F. (2006). El análisis del texto fílmico. Universitat Jaume I.

Halbwachs, M. (2002). Fragmentos de la memoria colectiva. Atenea Digital, 2. https://ddd.uab.cat/pub/ athdig/15788946n2/15788946n2a5.pdf

Lanza, P. (2010). Usos del archivo en el cine documental latinoamericano contemporáneo: los documentos sobrevivientes. Cine Documental, 1. http://revista. cinedocumental.com.ar/1/articulos_03.html

Ley 397 del 7 de agosto de 1997. Por la cual se desarrollan los artículos 70, 71 y 72 y demás Artículos concordantes de la Constitución Política y se dictan normas sobre patrimonio cultural, fomentos y estímulos a la cultura, se crea el Ministerio de la Cultura y se trasladan algunas dependencias. Diario Oficial, 43102. https://www.funcionpublica.gov. co/eva/gestornormativo/norma.php?i=337

Mazziotti, N. (2001) Los géneros en la televisión pública. Compilador: Omar Rincon. Bogotá: Convenio Andrés Bello. http://univirtual.utp.edu.co/pandora/ recursos/0/694/694.pdf

Nichols, B. (1997). La representación de la realidad. Paidós.

Noriega, E. (2012). Notas sobre found footage. Arte e Investigación, 8(14), 136-139. http://sedici.unlp. edu.ar/handle/10915/39764

Rincón, O. (2005). Televisión pública: del consumidor al ciudadano. Buenos Aires: La Crujía Ediciones.

Ronco-López, M. (2009). Los documentos audiovisuales y su conservación. En T. Agirreazaldegi e I. Camacho (Eds.), Los servicios de documentación en los medios de comunicación del País Vasco (pp. 73-100). Universidad del País Vasco. http://eprints. rclis.org/15786/1/4.pdf

Rubín de Celis, A. \& S. (2010). Los desafíos de la realidad. Una entrevista con Patricio Guzmán. DOC On-line, 8, 254-274. www.doc.ubi.pt. 
Seydel, U. (2014). La constitución de la memoria cultural. Acta Poética, 35(2), 187-214. doi: https://doi. org/10.1016/s0185-3082(14)72425-3

Unesco. (2006). Radiotelevisión de servicio público: un manual de mejores prácticas. San José: UNESCO.
Veliz, M. (2020). Archivos, familias y espectros en el documental latinoamericano contemporáneo. Culturales, 8, e453. doi: https://doi.org/10.22234/recu.20200801.e453 
Anexo 1. Tabla de codificación de documentales analizados

\begin{tabular}{|c|c|c|c|c|c|}
\hline \multicolumn{6}{|c|}{ Clasificación interna del canal de documentales } \\
\hline Código & Clasificación interna & Fecha de emisión & Tiempo & Formato & $\begin{array}{l}\text { Código } \\
\text { de Barras }\end{array}$ \\
\hline DOC0001 & 20070330 & $1 / 07 / 98$ & 29:18:00 & DVD & 3759 \\
\hline DOC0003 & 20070330 & $13 / 08 / 98$ & 24:19:00 & ВСТ30 & 3761 \\
\hline DOC0005 & 20070330 & $17 / 08 / 98$ & 24:00:00 & ВСТ30 & 3763 \\
\hline DOC0006 & 20070330 & $1 / 07 / 98$ & 29:18:00 & & \\
\hline DOC0007 & 20070330 & $1 / 08 / 98$ & $21: 00$ & & 3765 \\
\hline DOC0008 & 20070330 & $1 / 11 / 98$ & 25:00:00 & & 3766 \\
\hline DOC0009 & 20070330 & & $31: 05: 00$ & & 3767 \\
\hline DOC0010 & 20070330 & 1/08/98 & $0: 00$ & & 3768 \\
\hline DOC0012 & 20070330 & & 20:01 & & 3770 \\
\hline DOC0013 & 20070911 & 16/09/99 & $56: 56: 00$ & & 3771 \\
\hline DOC0014 & 20070330 & & 24:15:00 & & 3772 \\
\hline DOC0015 & 20070330 & 1/07/98 & $0: 00$ & & 3773 \\
\hline DOC0015 & 20070330 & & 30:00:00 & & 3773 \\
\hline DOC0017 & 20070330 & 1/08/98 & 0:00 & & 3775 \\
\hline DOC0018 & 20070330 & & $18: 30$ & & 3776 \\
\hline DOC0019 & 20070330 & $27 / 05 / 98$ & $30: 24: 00$ & ВТС60 & 3777 \\
\hline DOC0019 & 20070330 & 18/08/99 & 33:35:00 & & 3777 \\
\hline DOC0020 & 20070330 & & $22: 20$ & & 3778 \\
\hline DOC0021 & 20070330 & 7/03/98 & $18: 41$ & & 3779 \\
\hline DOC0022 & 20070330 & & 24:02:00 & & 3780 \\
\hline DOC0023 & 20070330 & & $5: 55$ & & 3781 \\
\hline DOC0025 & 20070330 & 1/04/99 & 28:21:00 & & 3783 \\
\hline DOC0026 & 20070330 & 10/04/99 & $15: 56$ & & 3784 \\
\hline DOC0027 & 20070330 & & 30:08:00 & & 3785 \\
\hline DOC0028 & 20070330 & $12 / 12 / 97$ & $10: 00$ & & 3787 \\
\hline DOC0029 & 20070330 & $1 / 12 / 97$ & $3: 43$ & & \\
\hline DOC0030 & 20070330 & $5 / 04 / 99$ & 24:06:00 & & 3788 \\
\hline DOC0033 & 20070330 & & 28:00:00 & & 3791 \\
\hline DOC0038 & 20070330 & 1/06/99 & 25:13:00 & & 3796 \\
\hline DOC0039 & 20070330 & 1/07/99 & $21: 20$ & & 3797 \\
\hline DOC0141 & 20071126 & $26 / 11 / 07$ & $23: 28$ & & 3901 \\
\hline DOC0145 & 20071126 & 7/08/07 & 28:45:00 & & 3905 \\
\hline DOC0149 & 20080218 & 16/02/08 & 26:05:00 & & 3844 \\
\hline DOC0150 & 20080729 & 18/07/08 & 55:08:00 & & 3908 \\
\hline & ISSN 0122 & $\begin{array}{l}\text { enul } \\
8 \bullet V_{0}\end{array}$ & & . & Continúa \\
\hline
\end{tabular}




\begin{tabular}{|c|c|c|c|c|c|}
\hline \multicolumn{6}{|c|}{ Clasificación interna del canal de documentales } \\
\hline Código & Clasificación interna & Fecha de emisión & Tiempo & Formato & $\begin{array}{l}\text { Código } \\
\text { de Barras }\end{array}$ \\
\hline DOC0152 & 20081217 & $1 / 12 / 08$ & 26:53:00 & & 3910 \\
\hline DOC0152 & 20081217 & $1 / 12 / 08$ & 28:07:00 & & 3910 \\
\hline DOC0153 & 20090126 & $25 / 12 / 08$ & 50:00:00 & & 3911 \\
\hline DOC0154 & 20090126 & $14 / 11 / 08$ & 24:00:00 & & 3912 \\
\hline DOC0155 & 20090126 & $14 / 11 / 08$ & 40:00:00 & & 3913 \\
\hline DOC0156 & 20090206 & $15 / 12 / 08$ & 55:03:00 & & 3914 \\
\hline DOC0157 & 20090304 & $15 / 12 / 08$ & $59: 15: 00$ & & 3915 \\
\hline DOC0158 & 20090309 & 9/03/09 & $23: 50$ & & 3916 \\
\hline DOC0159 & 20090526 & $5 / 05 / 09$ & $31: 15: 00$ & & 3917 \\
\hline DOC0160 & 20090702 & 15/06/09 & 43:17:00 & & 3918 \\
\hline DOC0162 & 20090825 & 17/08/09 & $16: 14$ & & 3920 \\
\hline DOC0163 & 20090825 & 17/08/09 & $1: 02: 55$ & & 3921 \\
\hline DOC0165 & 20090902 & 13/05/09 & 60:00:00 & & 3923 \\
\hline DOC0167 & 20090928 & 8/09/09 & 29:14:00 & & 3925 \\
\hline DOC0168 & 20091117 & 15/04/09 & 53:00:00 & ALT & 3926 \\
\hline DOC0174 & 20091229 & 29/12/09 & 26:38:00 & ALT & 3932 \\
\hline DOC0175 & 20091229 & 2/11/09 & $25: 34: 00$ & ALT & 3933 \\
\hline DOC0176 & 20091229 & $22 / 11 / 09$ & 24:13:00 & ALT & 3934 \\
\hline DOC0177 & 20100121 & 22/12/09 & $54: 46: 00$ & XDCAM23 & 3935 \\
\hline DOC0179 & 20100203 & 25/12/09 & $22: 15$ & ВСТ30 & 3937 \\
\hline DOC0180 & 20100405 & $30 / 03 / 10$ & $23: 17$ & ВСТ30 & 3938 \\
\hline DOC0186 & 20100818 & 9/08/10 & $43: 52: 00$ & DVCAM64 & 3943 \\
\hline DOC0188 & 20100927 & $1 / 11 / 10$ & $1: 23: 00$ & DVCAM64 & 3945 \\
\hline DOC0199 & 20101229 & 8/10/10 & $54: 34: 00$ & DVCAM64 & 3956 \\
\hline DOC0200 & 20101229 & $4 / 11 / 10$ & 54:52:00 & DVCAM64 & 3957 \\
\hline DOC0201 & 20101229 & $16 / 12 / 10$ & $50: 54: 00$ & DVCAM64 & 3958 \\
\hline DOC0202 & 20110103 & $23 / 10 / 10$ & $23: 43$ & DVCAM64 & 3959 \\
\hline DOC0202 & 20110103 & $16 / 10 / 10$ & 24:52:00 & DVCAM64 & 3959 \\
\hline DOC0202 & 20110103 & $9 / 10 / 10$ & 26:59:00 & DVCAM64 & 3959 \\
\hline DOC0203 & 20110103 & $17 / 10 / 10$ & $21: 57$ & DVCAM64 & 3960 \\
\hline DOC0203 & 20110103 & $13 / 11 / 10$ & $22: 10$ & DVCAM64 & 3960 \\
\hline DOC0203 & 20110103 & $10 / 10 / 10$ & 24:53:00 & DVCAM64 & 3960 \\
\hline DOC0204 & 20110103 & $24 / 10 / 10$ & $20: 29$ & DVCAM64 & 3961 \\
\hline DOC0204 & 20110103 & $31 / 10 / 10$ & $22: 29$ & DVCAM64 & 3961 \\
\hline DOC0204 & 20110103 & $30 / 10 / 10$ & $22: 54$ & DVCAM64 & 3961 \\
\hline & ISSN 0122 & en & 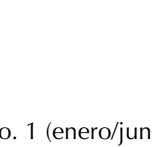 & 0 & Continúa \\
\hline
\end{tabular}




\begin{tabular}{|c|c|c|c|c|c|}
\hline \multicolumn{6}{|c|}{ Clasificación interna del canal de documentales } \\
\hline Código & Clasificación interna & Fecha de emisión & Tiempo & Formato & $\begin{array}{c}\text { Código } \\
\text { de Barras }\end{array}$ \\
\hline DOC0205 & 20110103 & $14 / 11 / 10$ & 25:00:00 & DVCAM64 & 3962 \\
\hline DOC0206 & 20110103 & $28 / 11 / 10$ & $21: 58$ & DVCAM64 & 3963 \\
\hline DOC0206 & 20110103 & $7 / 11 / 10$ & $22: 00$ & DVCAM64 & 3963 \\
\hline DOC0206 & 20110103 & $7 / 11 / 10$ & $22: 19$ & DVCAM64 & 3963 \\
\hline DOC0207 & 20110103 & $21 / 11 / 10$ & 24:00:00 & DVCAM64 & 3964 \\
\hline DOC0207 & 20110103 & $27 / 11 / 10$ & 24:00:00 & DVCAM64 & 3964 \\
\hline DOC0207 & 20110103 & $20 / 11 / 10$ & 24:48:00 & DVCAM64 & 3964 \\
\hline DOC0208 & 20110103 & $4 / 12 / 10$ & $22: 13$ & DVCAM64 & 3965 \\
\hline DOC0208 & 20110103 & $14 / 11 / 10$ & $22: 32$ & DVCAM64 & 3965 \\
\hline DOC0208 & 20110103 & $1 / 01 / 11$ & 24:10:00 & DVCAM64 & 3965 \\
\hline DOC0209 & 20110103 & $2 / 01 / 11$ & $21: 57$ & DVCAM64 & 3966 \\
\hline DOC0209 & 20110103 & $18 / 12 / 10$ & $23: 35$ & DVCAM64 & 3966 \\
\hline DOC0210 & 20110119 & $9 / 12 / 10$ & $54: 13: 00$ & DVCAM64 & 3967 \\
\hline DOC0211 & 20110119 & $11 / 11 / 10$ & 53:39:00 & DVCAM64 & 3968 \\
\hline DOC0212 & 20110119 & $14 / 10 / 10$ & $54: 10: 00$ & DVCAM64 & \\
\hline DOC0213 & 20110119 & $23 / 12 / 10$ & $50: 17: 00$ & MDVCAM & 3969 \\
\hline DOC0215 & 20110527 & $17 / 07 / 10$ & 55:00:00 & BTC60 & \\
\hline DOC0216 & 20110623 & $23 / 06 / 11$ & 37:39:00 & BTC60 & \\
\hline DOC0217 & 20111005 & $5 / 05 / 11$ & 1:00:00 & XDCAM50 & \\
\hline DOC0218 & 20111005 & $9 / 09 / 11$ & 29:34:00 & XDCAM50 & \\
\hline DOC0220 & 20111019 & 6/10/11 & $54: 37: 00$ & XDCAM23 & \\
\hline DOC0221 & 20111024 & 13/10/11 & $52: 52: 00$ & XDCAM23 & 8232 \\
\hline DOC0222 & 20111024 & $20 / 10 / 11$ & $52: 45: 00$ & XDCAM23 & 8233 \\
\hline DOC0223 & 20111116 & $11 / 11 / 11$ & 25:53:00 & XDCAM23 & 9551 \\
\hline DOC0224 & 20111212 & 19/11/09 & 0:00 & XDCAM23 & 15151 \\
\hline DOC0228 & 20111226 & & 31:13:00 & XDCAM23 & 15171 \\
\hline DOC0231 & 20111228 & $23 / 06 / 11$ & 54:00:00 & XDCAM50 & 16160 \\
\hline DOC0235 & 20120113 & $1 / 01 / 12$ & $58: 46: 00$ & DVCAM64 & 16164 \\
\hline DOC0236 & 20120116 & $14 / 12 / 11$ & 50:00:00 & XDCAM50 & 16165 \\
\hline DOC0242 & 20120420 & $11 / 03 / 12$ & 51:30:00 & DVCAM64 & 16171 \\
\hline DOC0243 & 20120522 & $10 / 05 / 12$ & 60:13:00 & DVD & 16172 \\
\hline DOC0246 & 20121224 & $7 / 12 / 12$ & $24: 17: 00$ & XDCAM23 & \\
\hline DOC0247 & 20130301 & $12 / 02 / 13$ & 54:11:00 & XDCAM50 & \\
\hline DOC0248 & 20130514 & $1 / 05 / 13$ & 55:35:00 & XDCAM50 & \\
\hline DOC0249 & 20130617 & $7 / 12 / 12$ & 1:28:29 & XDCAM50 & \\
\hline
\end{tabular}




\begin{tabular}{cccccc}
\hline \multicolumn{5}{c}{ Clasificación interna del canal de documentales } \\
\hline Código & Clasificación interna & Fecha de emisión & Tiempo & Formato & $\begin{array}{c}\text { Código } \\
\text { de Barras }\end{array}$ \\
\hline DOC0251 & 20130801 & $10 / 06 / 13$ & $58: 27: 00$ & XDCAM50 & \\
DOC0252 & 20130831 & $19 / 08 / 13$ & $51: 53: 00$ & XDCAM50 & \\
DOC0253 & 20130918 & $1 / 09 / 13$ & $38: 01: 00$ & XDCAM50 \\
DOC0254 & 20131017 & $13 / 10 / 13$ & $25: 40: 00$ & XDCAM50 \\
DOC0255 & 20131112 & $14 / 10 / 13$ & $54: 58: 00$ & XDCAM50 \\
DOC0258 & 20131120 & $13 / 05 / 13$ & $35: 15: 00$ & DVD \\
DOC0260 & 20131121 & $4 / 11 / 13$ & $0: 41: 23$ & XDCAM50 \\
DOC0262 & 20131128 & $14 / 10 / 13$ & $10: 00$ & DVD \\
DOC0264 & 20131128 & $20 / 07 / 13$ & $30: 00: 00$ & DVD \\
\hline
\end{tabular}

Fuente: canal Telemedellín (2014). 